\title{
NUMERICAL STUDY OF LAMINAR FORCED CONVECTION OF NANOFLUID IN A NEW MICROCHANNEL HEAT SINK
}

\author{
BOUHABEL Bourhane ${ }^{1}$, KABAR Yassine ${ }^{1}$ \\ ${ }^{1}$ Laboratoire Mécanique et systèmes énergétiques avancés, Ecole Nationale Polytechnique \\ de Constantine, BP 75, Nouvelle ville RP, Constantine, Algeria, e-mail: bourhane18@gmail.com, \\ yassine.kabar@enp-constantine.dz
}

\begin{abstract}
The heat transfer and pressure drop in a microchannel heat sink with 02 mixing chambers with inclined walls were numerically studied. The transport equations have been resolved by the finite volume method using ANSYS Fluent software. The operating fluids are water and $\mathrm{Al} 2 \mathrm{O} 3$-water. The results obtained for Reynolds numbers ranging from 187 and 705 show that adding a micro-mixing chamber with a rectangular rib in the microchannel improves the heat transfer and increases the pressure drop compared to conventional microchannels. The new shape of the mixing chamber studied shows a net decrease in pressure drop, which improves the performance of the micro heat sink by $5.6 \%$.
\end{abstract}

KEYWORDS: Nanofluid, Microdissipator, Mixing chamber, Nusselt number.

\section{Introduction}

The microchannel heat sink is one of the most widely used instruments for cooling micro-scale heat sources. The heat transfer and the pressure drop are the two parameters that can be used to control the efficiency of the heat sink. Chai et al. [1] made three different shapes of heat sinks and found that the perturbation of the thermal boundary layer produces an enhancement on the heat transfer with increased pressure drop. Another experimental study of chai et al. [2] consists of introducing two microchambers with rectangular shaped ribs along the microchannels, which results in high heat dissipation, and for the objective of penalizing pressure drops. Chai et al. [3], Kok-Cheong Wong and Jian-Hong Lee [4] made a numerical analysis of the microchannels with a mixing microchamber for different shapes of ribs, rectangular, triangular, elliptical, and diamond. They have found that the elliptical shape provides the best heat dissipation by a good pressure drop, Naresh et al [5] study the scaling effect on mixing efficiencies and pressure drops in the passive micromixers. They conclude increasing the width decreases the mixing efficiencies. Also, pressure drops reduce with increase in the depth of the channel. Many authors have investigated the influence of nanofluids on microchannels. For example, Ayoub Abdollahi et al. [6] the students have been numerically studying the effect of $\mathrm{Al} 2 \mathrm{O} 3$ nanofluid in the microchannels with a mixture microchamber, another experimental study on microchannels with nanofluids realized by Hamdi E. Ahmed et al. [7], a comparison between different types of nanofluids made by Tu-Chieh Hung et al. [8] for the reason of obtaining the best kind of nanoparticles which can be mixed with the base fluid to get the best heat dissipation.

In our numerical study, we thought of making an inclination at the entrance and exit of the mixing chamber in which the fluid flow becomes well structured and see the effect of divergence and convergence at the inlet and outlet of the microchamber, respectively, to have the impact of the $\mathrm{Al} 2 \mathrm{O} 3$-water nanofluid on the heat transfer and pressure drop. 


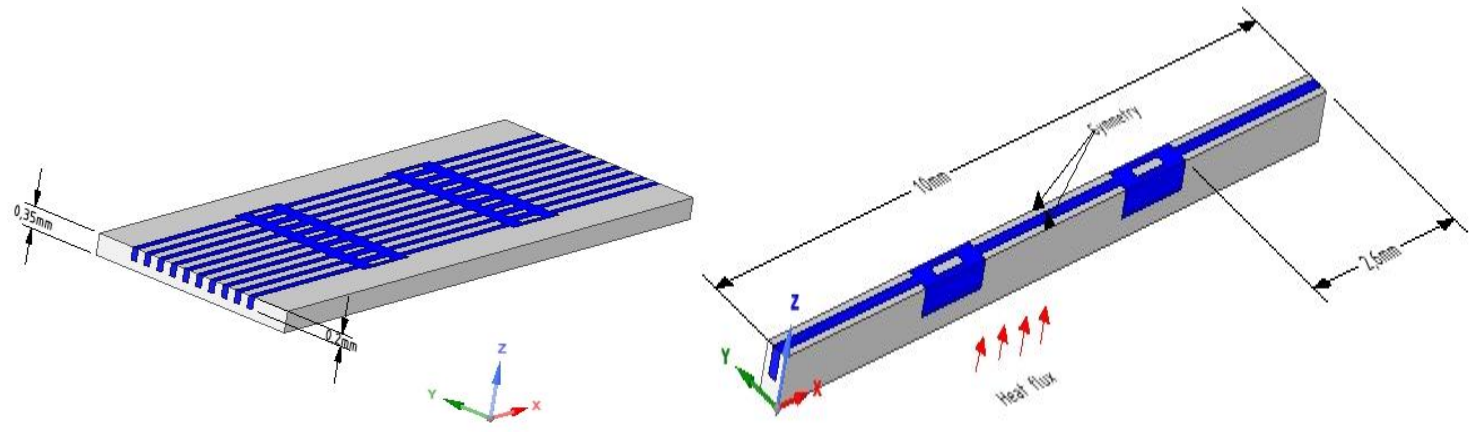

Fig. 1 Geometry of the problem

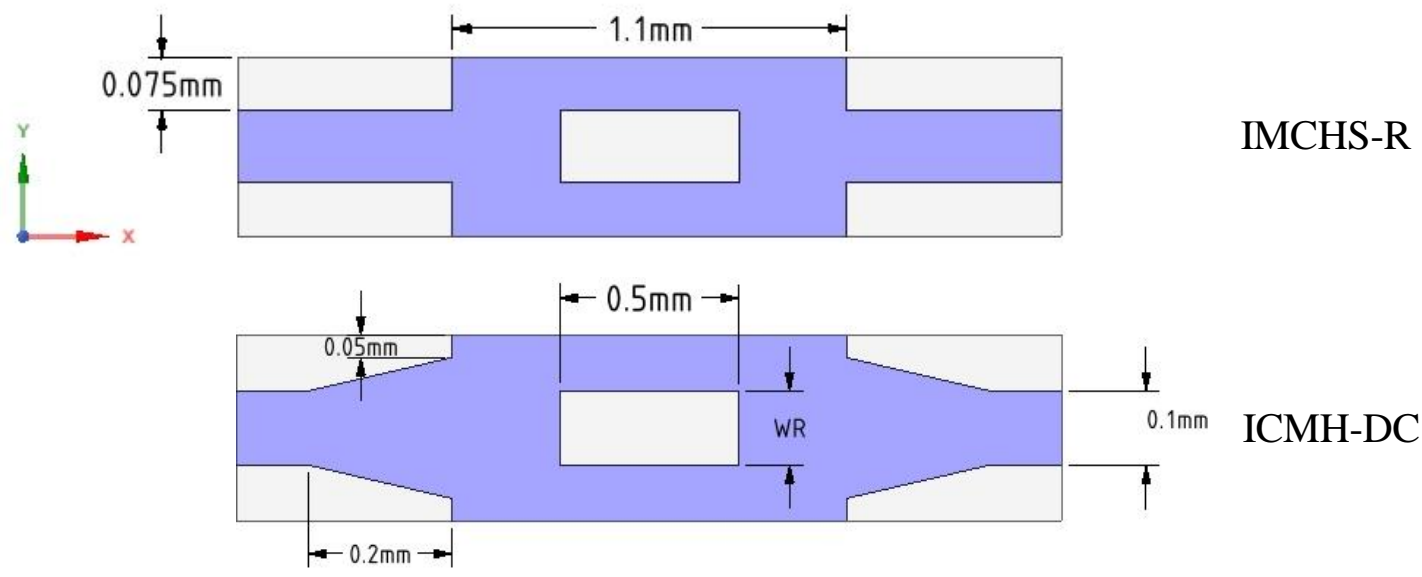

Fig. 2 form of microchamber

Figure 1 shows the microchannel heat sink with dimensions $10 \mathrm{~mm} \times 8 \mathrm{~mm} \times 0.35 \mathrm{~mm}$, it is composed of 10 microchannels with $0.20 \mathrm{~mm}$ height and $0.1 \mathrm{~m}$ width. This heat sink is placed above a heat source; it contains two mixing chambers with rectangular obstacles in the middle of the chambers. Two geometric shapes of the mixing chamber have been studied, with and without chamfer at the entrance and exit of the chambers as shown in figure 2. The modelling of the forced convection with the following hypotheses: three-dimensional flow, incompressible, laminar flow, the effect of gravity and other forms of body forces are negligible. The dynamic viscosity, density, and specific water heat are defined as piecewise linear functions in table 1 . The viscous dissipation is taken into account. The equations of continuity and Navier-stocks are thus:

$$
\begin{gathered}
\frac{\partial}{\partial x_{i}}\left(\rho u_{i}\right)=0 \\
\frac{\partial}{\partial x_{i}}\left(\rho_{f} u_{i} u_{j}\right)=-\frac{\partial p}{\partial x_{j}}+\frac{\partial}{\partial x_{i}}\left[u_{f}\left(\frac{\partial u_{j}}{\partial u_{i}}+\frac{\partial u_{i}}{\partial u_{j}}\right)\right]
\end{gathered}
$$

The equation of energy is:

For the fluid: 


$$
\frac{\partial}{\partial x_{i}}\left(\rho_{f} u_{i} c_{p f} T\right)=\frac{\partial}{\partial x_{i}}\left(K_{f} \frac{\partial T}{\partial x_{i}}\right)+\mu_{f}\left[2\left(\frac{\partial u_{i}}{\partial u_{i}}\right)^{2}+\left(\frac{\partial u_{j}}{\partial u_{i}}+\frac{\partial u_{i}}{\partial u_{j}}\right)^{2}\right]
$$

For the solid

$$
\frac{\partial}{\partial x_{i}}\left(K_{s} \frac{\partial T}{\partial x_{i}}\right)=0
$$

Hydrodynamics boundary condition:

At the walls $\mathrm{u}=\mathrm{v}=\mathrm{w}=0$

At the inlet: $\mathrm{x}=0 \mathrm{~mm}, u_{f}=u_{\text {in }}$

At the outlet: $\mathrm{x}=10 \mathrm{~mm}, p_{f}=p_{\text {out }}=0$

Thermal boundaries conditions:

At $\mathrm{x}=0 \mathrm{~mm}, T_{f}=T_{\text {in }}=293 \mathrm{~K}$ for the fluid and $-k_{s}\left(\partial \mathrm{T}_{\mathrm{s}} / \partial \mathrm{x}\right)=0$ for the solid.

At $\mathrm{x}=10 \mathrm{~mm} ;-k_{f}\left(\partial \mathrm{T}_{\mathrm{f}} / \partial \mathrm{x}\right)=0$ for the fluid and $-k_{s}\left(\partial \mathrm{T}_{\mathrm{s}} / \partial \mathrm{x}\right)=0$ for the solide.

At $\mathrm{y}=0 \mathrm{~mm}$ and $\mathrm{y}=0.5 \mathrm{~mm}$, symmetry.

At $\mathrm{z}=0 \mathrm{~mm} ;-k_{s}\left(\partial \mathrm{T}_{\mathrm{s}} / \partial \mathrm{z}\right)=q=1 \mathrm{MW} / \mathrm{m}^{2}$

At $\mathrm{z}=0.35 \mathrm{~mm} ;-k_{s}\left(\partial \mathrm{T}_{\mathrm{s}} / \partial \mathrm{z}\right)=0 ;-k_{s}\left(\partial \mathrm{T}_{\mathrm{s}} / \partial \mathrm{n}\right)=-k_{f}\left(\partial \mathrm{T}_{\mathrm{f}} / \partial \mathrm{n}\right)$ which $\mathrm{n}$ is the normal vector.

\section{$3 \quad$ Numerical model}

The previous equations are solved by the finite volume method using the CFD code ANSYSFluent 18.1. Convective and diffusive fluxes are evaluated with the standard discretization scheme and the second-order discretization for the momentum and energy. The coupling of pressure and velocity is modeled by the SIMPLEC method. The numerical solution's convergence criterion is based on the sum of the normalized residuals for each variable. We consider the convergence when these residuals are lower than $10^{-6}$. The study of the independence of the mesh is presented in table 2 for three different numbers of nodes: 356070, 830327 and 1291205 in microchannel IMCHS-DC (WR $=0.12 \mathrm{~mm}$ ); Reynolds number is $\mathrm{Re}=441$, the Nusselt number, and the pressure drop coefficient are sufficient to perform the simulation with an error less than $1 \%$. The thermophysical properties of $\mathrm{AL}_{2} \mathrm{O}_{3}$ nanoparticles are presented in Table 3, and the new properties of the nanofluid $\mathrm{AL}_{2} \mathrm{O}_{3}$-water were determined from the following equations:

The density [6]:

$$
\rho_{n f}=(1-\phi) \rho_{f}+\phi \rho_{n p}
$$

The heat specific [6]:

$$
\left(\rho C_{p}\right)_{n f}=(1-\phi)\left(\rho C_{P}\right)_{f}+\phi\left(\rho C_{p}\right)_{n p}
$$

The dynamic viscosity gives by the Brinkman equation [10]:

$$
\mu_{e f f}=\frac{\mu_{f}}{\left(1-34.87\left(\frac{d_{n p}}{d_{f}}\right)^{-0.3} * \phi^{1.03}\right)}
$$

and

$$
d_{f}=0.1\left(\frac{6 M}{N \pi \rho_{f o}}\right)^{\frac{1}{3}}
$$


The thermal conductivity gives by the equation of Maxwell [10]:

$$
\frac{k_{e f f}}{k_{f}}=1+4.4\left(\frac{\rho_{f} u_{B} d_{n p}}{\mu_{f}}\right)^{0.4} \operatorname{Pr}^{0.66}\left(\frac{T}{T_{f r}}\right)^{10}\left(\frac{k_{n p}}{k_{f}}\right)^{0.03} \phi^{0.66}
$$

which

$$
u_{B}=\frac{2 \sigma T}{\pi \mu_{f} d_{n p}^{2}} ; \boldsymbol{\sigma}=1.680710^{-23} \mathrm{~J} / \mathrm{K}
$$

Table 1 . Thermophysical properties of water [1]

\begin{tabular}{ccccc}
\hline $\mathbf{T}(\mathbf{K})$ & $\boldsymbol{\rho}\left(\frac{\mathbf{k g}}{\mathbf{m}^{3}}\right)$ & $\boldsymbol{c}_{\boldsymbol{p}}\left(\frac{\mathbf{J}}{\mathbf{k g} \cdot \mathbf{K}}\right)$ & $\mathbf{k}\left(\frac{\mathbf{W}}{\mathbf{m} \cdot \mathbf{K}}\right)$ & $\boldsymbol{\mu}(\mathbf{k g} / \mathbf{m s})$ \\
\hline $\mathbf{2 9 3}$ & 998.2 & 4183 & 0.599 & 0.001004 \\
$\mathbf{3 0 3}$ & 995.7 & 4174 & 0.618 & 0.0008015 \\
$\mathbf{3 1 3}$ & 992.2 & 4174 & 0.635 & 0.0006533 \\
$\mathbf{3 2 3}$ & 988.1 & 4174 & 0.648 & 0.0005494 \\
$\mathbf{3 3 3}$ & 983.1 & 4179 & 0.659 & 0.0004699 \\
$\mathbf{3 4 3}$ & 977.8 & 4187 & 0.668 & 0.0004061 \\
$\mathbf{3 5 3}$ & 971.8 & 4195 & 0.674 & 0.0003551 \\
$\mathbf{3 6 3}$ & 965.3 & 4208 & 0.68 & 0.0003149 \\
\hline
\end{tabular}

Table 2. Study of the independence of a mesh, $\mathrm{Re}=441$ for IMCHS-DC $(\mathrm{WR}=0.12 \mathrm{~mm})$

\begin{tabular}{ccccc}
\hline & Nu & Error\% & fave & Error\% \\
\hline $\mathbf{3 5 6 0 7 0}$ & 8.713 & 2.81 & 0.0459 & 3.57 \\
$\mathbf{8 3 0 3 2 7}$ & 8.959 & 0.6 & 0.0472 & 0.84 \\
$\mathbf{1 2 9 1 2 0 5}$ & 8.965 & - & 0.0476 & - \\
\hline
\end{tabular}

Table 3. Thermophysical properties of $\mathrm{AL}_{2} \mathrm{O}_{3}$ [11]

\begin{tabular}{cc}
\hline $\begin{array}{c}\text { Thermophysical } \\
\text { properties }\end{array}$ & AL2O3 \\
\hline$\rho\left(\frac{\mathrm{kg}}{\mathrm{m}^{3}}\right)$ & 3970 \\
$c_{p}\left(\frac{\mathrm{J}}{\mathrm{kg} \cdot \mathrm{K}}\right)$ & 765 \\
$\mathrm{k}\left(\frac{\mathrm{W}}{\mathrm{m} \cdot \mathrm{K}}\right)$ & 40 \\
\hline
\end{tabular}

Figures 3 and 4 represent a comparison between our results and those presented by Chai et al. [1] [2]. They show good agreement and confirm the validity of the mathematical model used in the present study.

\section{$4 \quad$ Results and discussion}

The results obtained for the microchannel with mixing chamber containing a rectangular IMCHS-R rib and the new shape of the mixing chamber are shown for the mean Nusselt number and the mean friction coefficient for different Reynolds numbers.

Note that Reynold's number is given by:

$$
R e=\frac{\rho_{f} u_{m} D_{h}}{\mu_{f}}
$$




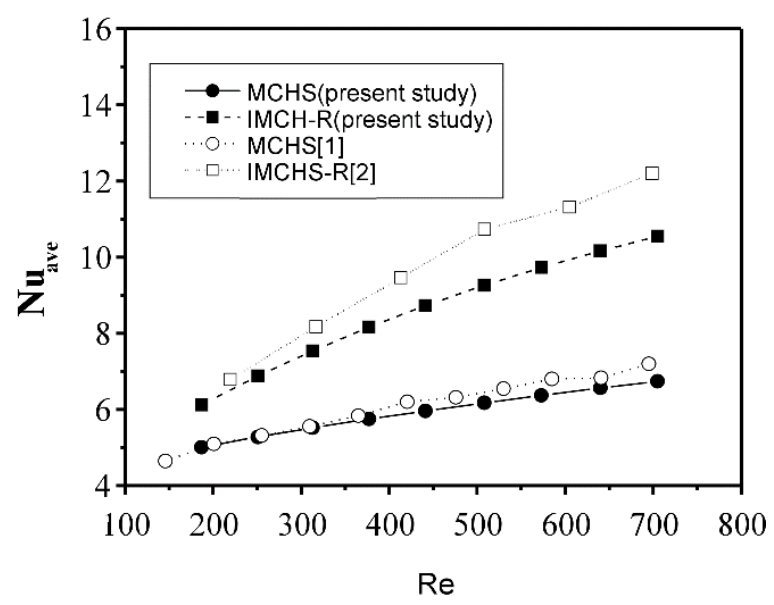

Fig. 3 variation of the Nusselt number as a function of the Reynolds

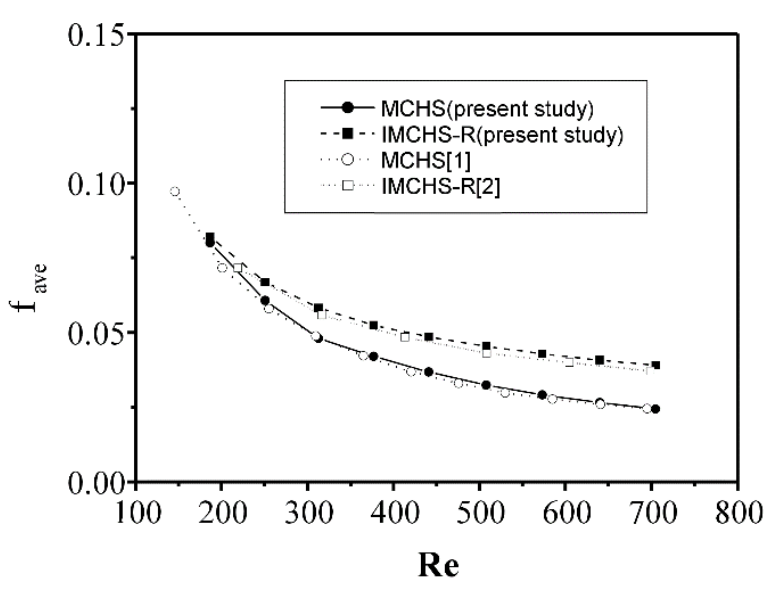

Fig. 4 variation of the friction coefficient as a function of Reynolds

The friction factor:

$$
f_{\text {ave }}=\frac{2 \Delta p D_{h}}{\rho_{f} L u_{m}^{2}}
$$

The heat transfer coefficient:

$$
h_{\text {ave }}=\frac{q A_{s}}{A_{c}\left(T_{w}-T_{f}\right)}
$$

$A_{s}$ and $A_{C}$ the base area of the heat sink and the contact area solid/fluid respectively. $T_{w}$ the average temperature of the base; $T_{f}$ the bulk temperature of the fluid.

The average Nusselt number:

$$
N u_{\text {ave }}=\frac{h_{\text {ave }} D_{h}}{k_{f}}
$$

To compare the new ICMH-DC micro-mixing chamber shape with the IMCH-R shape, the performance evaluation criterion is introduced which is defined as follows:

$$
\text { PEC }=\frac{h_{\text {ave }}}{h_{\text {ave }, 0}}=\frac{N u_{\text {ave }}}{N u_{\text {ave }, 0}}=\frac{N u_{\text {ave }} / N u_{\text {ave }, 0}}{\left(f_{\text {ave }} / f_{\text {ave }, 0}\right)^{1 / 3}}
$$

Such as $\mathrm{f}_{\mathrm{ave}, 0}$ and $\mathrm{Nu}_{\mathrm{ave}, 0}$ are the friction factor and the Nusselt number respectively for the conventional microchannel. 




(a)

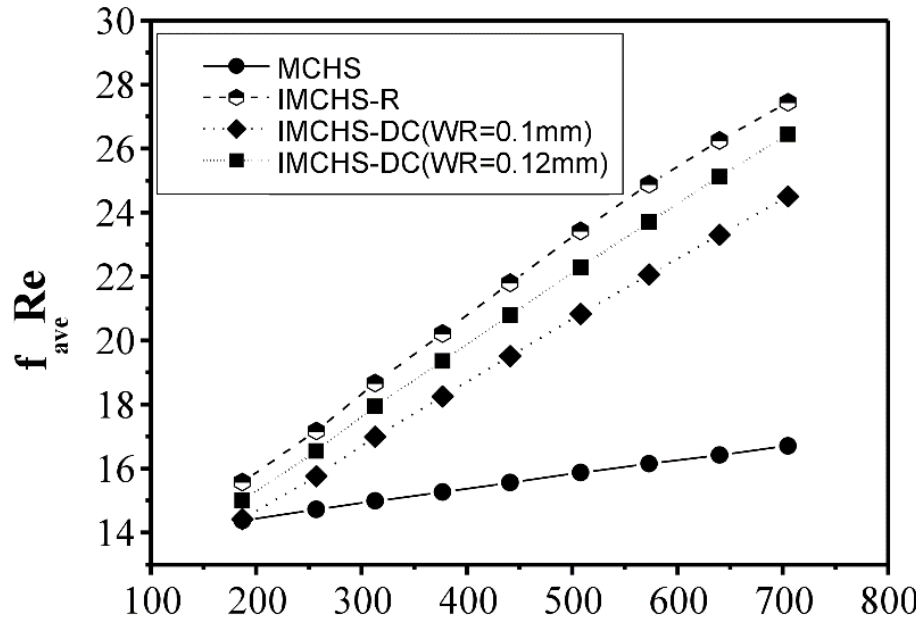

Re

(b)

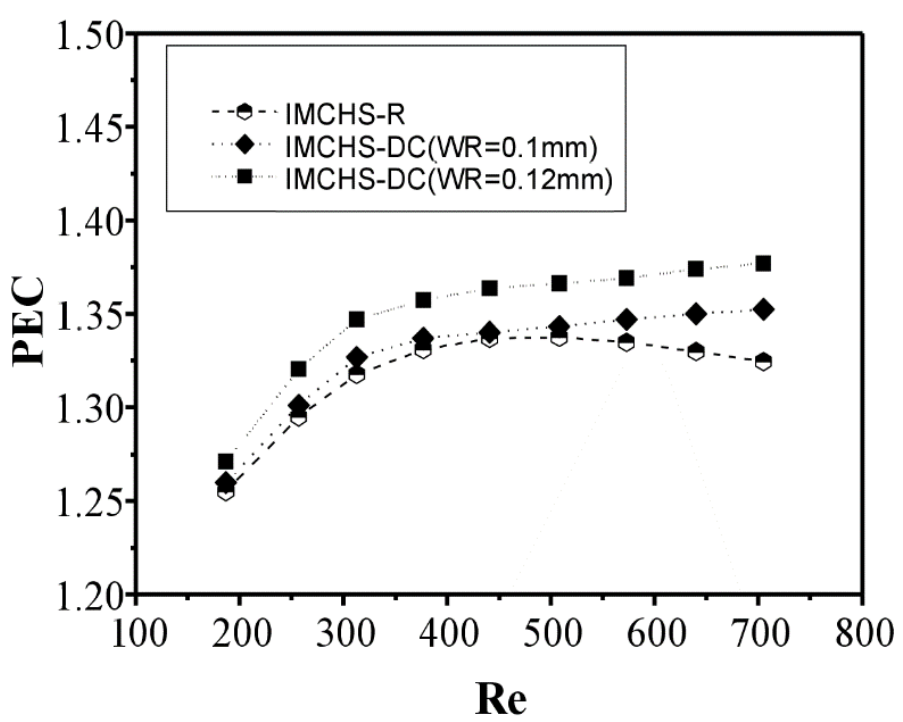

(c)

Fig. 5 variation of (a) pressure drop (b) Nuselth number (c) Performance evaluation criteria as a function of the Reynolds 


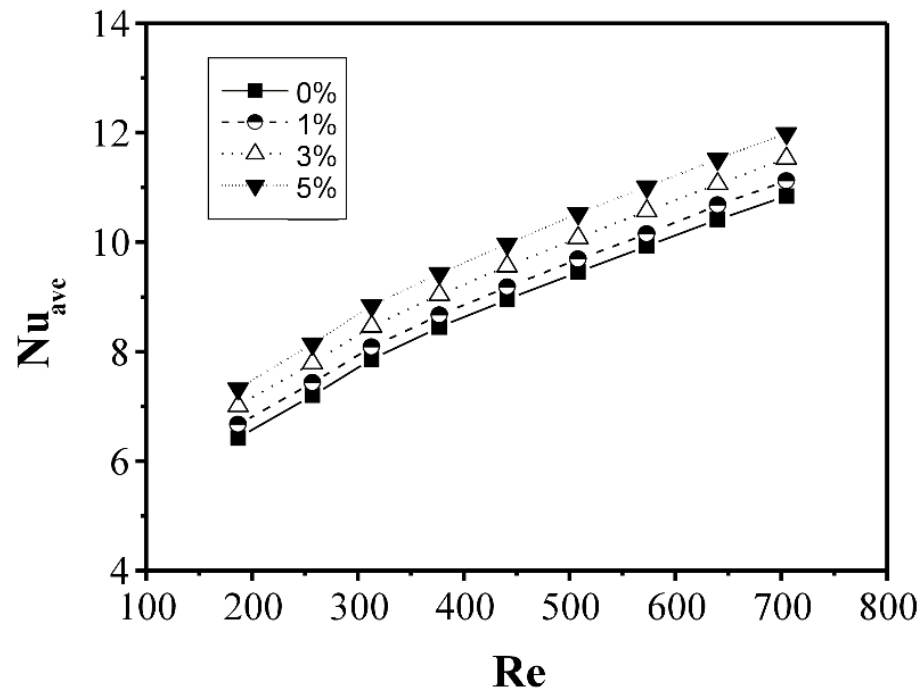

(a)



(b)



(c)

Fig. 6 variation of (a) pressure drop (b) Nusselt number (c) performance evaluation criteria as a function of Reynolds for IMCHS-DC(WR $=0.12 \mathrm{~mm})$ for different concentrations of the nanoparticles. 
Figure 5 represents the variation of the average Nusselt number as a function of Reynolds for the two forms of the mixing chamber. Note that the average number of nusselt obtained for the different Reynolds numbers is significantly improved in the presence of the mixing chamber. The influence of the mixing chamber shape is not important, $\mathrm{Nu}_{\mathrm{avr}}$ is of the same order for the three geometries containing a mixing chamber namely IMCHS-DC (WR $=0.12 \mathrm{~mm}$ ), IMCHS-R (WR $=0.1 \mathrm{~mm})$ and IMCHS-DC (WR $=0.1 \mathrm{~mm})$ for all Reynolds Re numbers. However the new shape of the mixing chamber gives a clear drop of the pressure losses for (WR $=0.1 \mathrm{~mm}$ ) compared to the IMCHS-R (WR $=0.1 \mathrm{~mm})$. To evaluate the efficiency of the heat sink, we use the performance evaluation criteria PEC which are shown in Figure 5.c as a function of Reynolds, The PEC obtained for the geometry IMCHS-DC(WR $=0.12 \mathrm{~mm})$ are larger than those obtained by the geometry IMCHS-DC $(\mathrm{WR}=0.1 \mathrm{~mm})$ and $\mathrm{IMCH}-\mathrm{R}(\mathrm{WR}=0.1 \mathrm{~mm})$. A clear improvement in the PEC obtained for the MCHS-DC $(\mathrm{WR}=0.1 \mathrm{~mm})$ geometry compared to the IMCH-R(WR = $0.1 \mathrm{~mm}$ ) geometry is noted for the large values of the Reynolds number (from $R e=500$ ), also chai et al. [2] found that the increase of width WR of the rectangular rib increases the heat transfer and the pressure drop, but from our study, we can increase WR by using the new shape of the mixing chamber so that the pressure drop stays lower than the microchannel (IMCH-R WR $=0.1 \mathrm{~mm}$ ).

Figure 6 represents the variation of the average Nusselt number, the average pressure drop, and the performance evaluation criteria coefficient as a function of Reynolds, respectively. It is found that the addition of $\mathrm{AL}_{2} \mathrm{O}_{3}$ nanoparticles to the working fluid increases the transfer with an increase of the pressure drop. The PEC becomes very important by increasing the volume concentration.

\section{CONCLUSION}

The previous simulation results allowed us to conclude many possibilities to enhance the heat transfer in a microchannel heat sink, such as the increase of the Reynolds number, the introduction of a mixing microchamber, or the use of nanofluids such as $\mathrm{Al}_{2} \mathrm{O}_{3}$. The new shape of the IMCHSDC mixing microchamber has given us a clear pressure drop, and it leads to minimizing the consumption of the pumping power of the fluid.

\section{NOMENCLATURE}

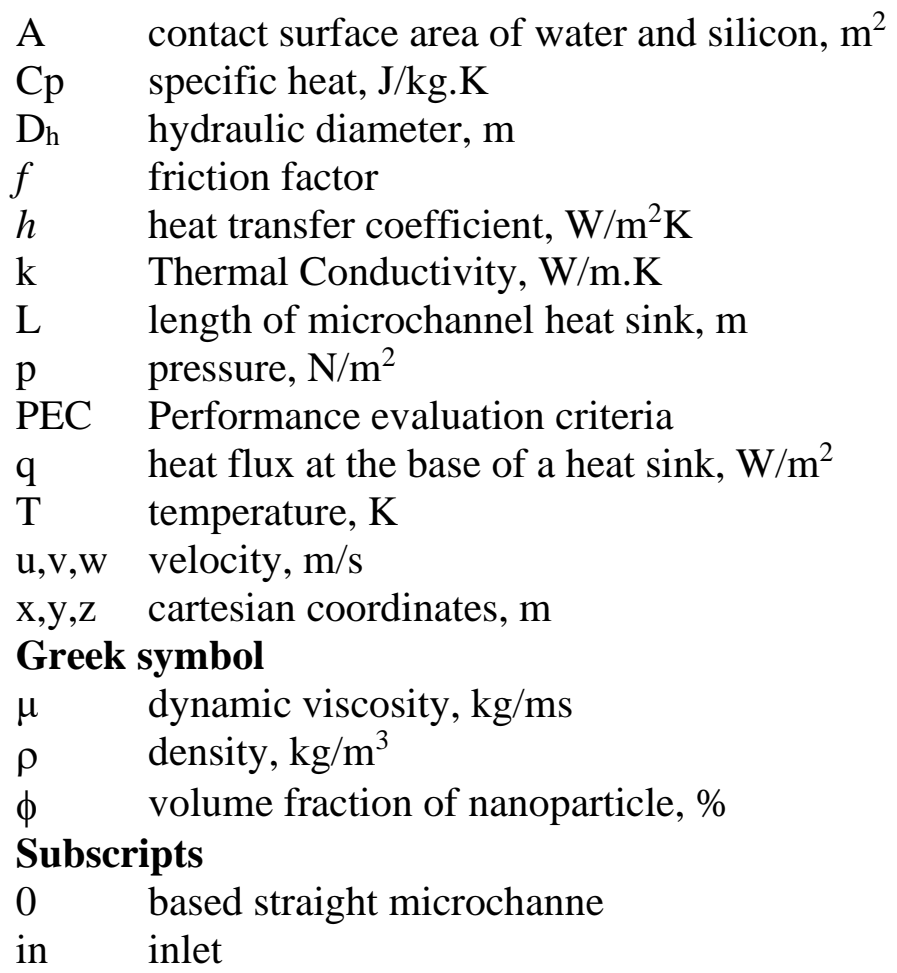




$\begin{array}{ll}\text { ave } & \text { average } \\ \mathrm{f} & \text { fluid } \\ \text { in } & \text { inlet } \\ \mathrm{m} & \text { mean } \\ \text { out } & \text { outlet } \\ \mathrm{s} & \text { solid } \\ \mathrm{nf} & \text { nanofluid } \\ \mathrm{np} & \text { nanoparticle }\end{array}$

\section{REFERENCES}

[1] Chai, L., Xia G.D., Wang L. "Heat transfer enhancement in microchannel heat sinks with periodic expansion-constriction cross-sections", International Journal of Heat and Mass Transfer 62, pp. 741 - 751, 2013. DOI: 10.1016/j.ijheatmasstransfer.2013.03.045

[2] Chai, L., Xia, G., Zhou, M., Li, J., Qi J. “ Optimum thermal design of interrupted microchannel heat sink with rectangular ribs in the transverse microchambers", Applied Thermal Engineering, 51 (2), pp. 880 - 889, 2013. DOI: 10.1016/j.applthermaleng .2012.10.037

[3] Chai, L. , Xia, G. D., Wang., H. S. "Laminar flow and heat transfer characteristics of interrupted microchannel heat sink with ribs in the transverse microchambers", International Journal of Thermal Sciences 110, pp. 1 - 11, 2016. DOI: 10.1016/j.ijthermalsci. 2016.06.029.

[4] Wong, K. C., Lee, J. H. "Investigation of thermal performance of microchannel heat sink with triangular ribs in the transverse microchambers", International Journal of Heat and Mass Transfer 65, pp. 103 - 110, 2015. DOI: 10.1016/j.icheatmasstransfer.2015.04.011

[5] Naresh, V., Bodas, D., Sunil, C., Tejashree B. "Geometrically Similar Rectangular Passive Micromixers And The Scaling Valididy On Mixing Efficiency And Pressure Drops", Strojnícky časopis - Journal of Mechanical Engineering 69 (1), pp. 69 - 84, 2019. DOI: $10.2478 /$ scjme-2019-0006

[6] Ayoub, A, Rajnish, N. S., Hussein, A. M., Ashkan, V. "Heat transfer and flow analysis of $\mathrm{Al}_{2} \mathrm{O}_{3}$-Water nanofluids in interrupted microchannel heat sink with ellipse and diamond ribs in the transverse microchambers", Heat Transfer Engineering, pp. 1461 - 1469, 2017. DOI: 10.1080/01457632.2017.1379344

[7] Hamdi, E., Ahmed, M. I., Ahmed, I., Seder, M. F., Salman, B. H. "Experimental investigation for sequential triangular double-layered microchannel heat sink with nanofluids", International Communications in Heat and Mass Transfer 77, pp. $104-115$, 2016. DOI: $10.1016 /$ j.icheatmasstransfer.2016.06.010

[8] Hung, T. C., Yan, W. M., Wang, X. D., Chang, C. Y. "Heat transfer enhancement in microchannel heat sinks using nanofluids", International Journal of Heat and Mass Transfer 55, pp. 2559 - 2570, 2012. DOI: 10.1016/j.ijheatmasstransfer.2012.01.004

[9] Mohammed, H., Gunnasegaran, P., Shuaib, N. "Heat transfer in rectangular microchannels heat sink using nanofluids", International Communications in Heat and Mass Transfer 37, pp. 1496 - 1503, 2010. DOI: 10.1016/j.icheatmasstransfer.2010.08.020

[10] Corcione, M. "Empirical correlating equations for predicting the effective thermal conductivity and dynamic viscosity of nanofluids", Energy Conversion and Management 52, pp. 789 - 793, 2011. DOI: 10.1016/j.enconman.2010.06.072 
[11] Abdollahi, A., Mohammed, H. A., Vanaki, S. M., Osia, A., Golbahar Haghighi, M. R. "Fluid flow and heat transfer of nanofluids in microchannel heat sink with V-type inlet/outlet arrangement", Alexandria Engineering Journal 56, pp. 161 - 170, 2017. DOI: 10.1016/j.aej.2016.09.019 